\title{
Concrete structures monitoring using ultrasonic tests
}

Alexandre Lorenzi (Main Author and Corresponding Author) Universidade Federal do Rio Grande do Sul, Laboratório de Ensaios e Modelos Estruturais (LEME) Av. Bento Gonçalves, 9500, Prédio 43436, Campus do Vale CEP 91509-90, Agronomia, Porto Alegre, RS (Brasil)

alexandre.lorenzi@ufrgs.br

\section{Kássio Stein}

Universidade Federal do Rio Grande do Sul, Laboratório de Ensaios e Modelos Estruturais (LEME) Av. Bento Gonçalves, 9500, Prédio 43436, Campus do Vale CEP 91509-90, Agronomia, Porto Alegre, RS (Brasil)

kassio86@hotmail.com

\section{Lucas Alexandre Reginatto}

Universidade Federal do Rio Grande do Sul, Laboratório de Ensaios e Modelos Estruturais (LEME) Av. Bento Gonçalves, 9500, Prédio 43436, Campus do Vale

CEP 91509-90, Agronomia, Porto Alegre, RS (Brasil)

alexandre.lorenzi@ufrgs.br

https://orcid.org/0000-0001-7944-6440

\section{Luiz Carlos Pinto da Silva Filho}

Universidade Federal do Rio Grande do Sul, Laboratório de Ensaios e Modelos Estruturais (LEME) Av. Bento Gonçalves, 9500, Prédio 43436, Campus do Vale

CEP 91509-90, Agronomia, Porto Alegre, RS (Brasil)

Icarlos66@gmail.com

https://orcid.org/0000-0003-3703-7328

Manuscript Code: 13722

Date of Acceptance/Reception: 15.09.2020/15.10.2019

DOI: 10.7764/RDLC.19.3.

\begin{abstract}
Due to the nature of their use, concrete structures are typically subjected to various aggressive actions derived from the loads and the environmental agents, which make the concrete condition change over time. Constant monitoring of structures is a necessary procedure since the preventive detection of problems allows the use of more straightforward and cost-effective methods for evaluation and repair. In order to carry out continuous monitoring of the state condition of concrete elements, there are many tools available. Nondestructive Testing (NDT) applications are a new strategy to monitor the state of concrete structures continually. Recent advancements in NDT technologies are increasingly turning them into attractive and viable strategies to support this type of monitoring and visual inspection. In particular, besides been viable and attractive, ultrasonic tests are a relatively cheap alternative and represent a range of different methods, each one with its benefits, to analyze concrete structures. The Research Group of LEME-UFRGS has developed research and application of NDT methods in general, and ultrasonic based methods in particular, for the last 15 years. The research done by the group demonstrates that these methods can contribute to monitoring deterioration and the quality of concrete structures. The present study demonstrates particular cases involving ultrasonic pulse testing and ultrasonic tomography. The aim was to check for these technique improvements for the analysis of concrete elements. The results highlight the potentialities and shortcomings of each technique.
\end{abstract}

Keywords: NDT, structures monitoring, concrete structures, ultrasonic pulse velocity, ultrasonic tomography.

Concrete properties can vary considerably depending on the nature and proportions of the constituents, the construction methods, and the environmental conditions. Therefore, the development of methods to determine the state condition and ascertain the quality of concrete elements is critical (Lorenzi, Campagnolo, \& Silva Filho, 2006).

Nowadays, despite its shortcomings, compressive strength is still mostly used as the single control property to monitor and indicate the quality and homogeneity of the concrete. In order to improve this undesirable situation, other test methods have been investigated, to find ways to foster better monitoring and inspection of concrete structures. In this direction, there is an increasing interest in using NDT techniques, which have shown promising results in laboratory and situ studies. Therefore, they are being considered as a complementary or stand-alone alternative to ascertain and check over time the state condition of concrete structures. 
One of the advantages is that most NDT methods allow the detection of defects without damaging the material. Moreover, they make it possible to inspect without service interruption, with savings in terms of time and costs (Grabowski, Padaratz \& Pinto, 2008).

The challenge nowadays is to define the best NDT technique for each use. Damage in concrete structures many times take the form of distributed micro-cracks, such as that caused by freeze-thaw action, or is made evident as distinct large cracks that extend for significant distances within the structure. Techniques that can detect, localize, and characterize this damage using NDT are of great interest to practicing structural engineers. In these cases, the use of mechanical wave-based test methods, such as ultrasonic and sonic approaches, enables engineers to inspect inner layers of the concrete structure and may offer information concerning effective elastic constants and presence of flaws or damaged areas (Shah, Popovics, Subramaniam \& Aldea, 2000).

The monitoring of the condition of the concrete subsurface is of particular importance since this is the layer in direct contact with the outside environment (Chekround, Le Marrec, Abraham, Villain \& Durand, 2009). Furthermore, the ability to detect internal compacity and flaws is essential, since the durability of concrete elements depends much on porosity and permeability to water and air. These changes in density and porosity, as well as in the elastic modulus, are well established and can be closely correlated to changes in ultrasonic velocity. Hence, NDT techniques based on this principle are quite useful to gather data regarding quality that may affect the service life. Therefore, ultrasonic techniques are promising ways to collect critical information regarding the microstructure and transport characteristics of cementitious materials (Molero Armenta, Segura, Hernández, Garcia Izquierdo \& Anaya, 2009).

Literature Review

\section{Research Gap}

The application of nondestructive evaluation (NDE) methods for quality assurance of concrete structures has made considerable progress recently. Driven by the technology and the knowledge transferred from other areas of materials testing and medicine, a versatile toolbox of methods for the investigation of reinforced concrete structures has emerged from research (Wiggenhauser, 2009).

The condition assessment of building materials is a crucial point to reassess existing structures whose material aging can have resulted in some performance loss and some deterioration of the safety level. Progressive decay of performance also induces significant maintenance costs, such as those to prevent future deterioration and ultimate failure. NDT is widely used in civil engineering for controlling new structures (quality control) as well as for assessing the level of The purposes of NDT can be classified as follows (damage to old structures and buildings whose behavior is under question.

The purposes of NDT can be classified as follows (Breysse, 2009):

a) to detect a defect or a variation of properties, between two structures or inside one structure,

b) to build a hierarchy, regarding a given property, among several areas in a structure or several structures,

c) to quantify these properties.

The problems frequently encountered by NDT experts are related to three types of problems (Breysse, 2009):

a) identifying the material properties: (1) estimation of on-site compressive strength of concrete, (2) assessment of concrete condition and damage after an accidental fire,

b) detection of defects: (1) detecting voids in cable ducts, (2) detecting and identifying debonding problems, delaminations or interfaces, (3) monitoring or detecting failure in cable structures,

c) problems with unknown geometry: control of the thickness of a pavement and pile examination.

Increasing needs involving pathological diagnosis of concrete structures imply the necessity of NDE methods. Diagnosis reliability and degradation prediction of concrete structures represent a tremendous economic stake (Ploix, Garnier, Breysse \& Moysan, 2011). Nevertheless, it is necessary to map the potentialities and shortcomings of each method to decide when each of them may be useful and reliable.

In order to contribute to this situation, the present work presents the results of four case studies that used two NDT methods to detect internal defects in reinforced concrete structures: Ultrasonic Tomography (UT) and Ultrasonic Pulse Velocity (UPV). The main objective was to determine if there were any concrete voids or failures that compromise the proper functioning of the structures. The study analyzed two types of equipment: a more advanced and sophisticated 3D Ultrasonic Tomographer and more straightforward and more widely used UPV Pulse portable equipment. Figure 1 
illustrates both. Before discussing the results, this study presents a short review of the working principles of both types of equipment.

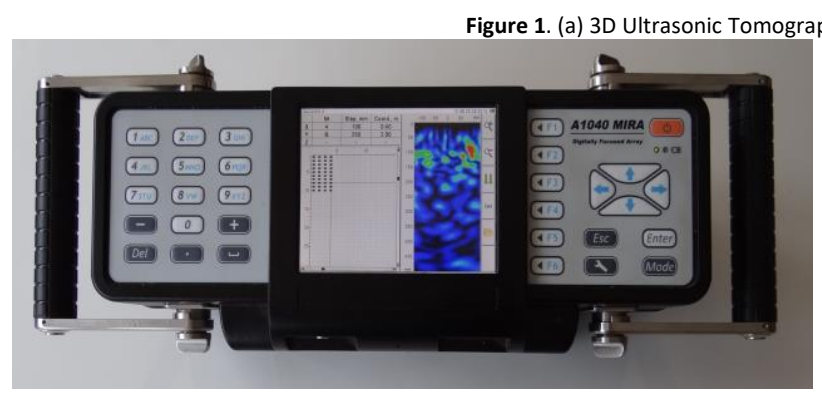

(a)

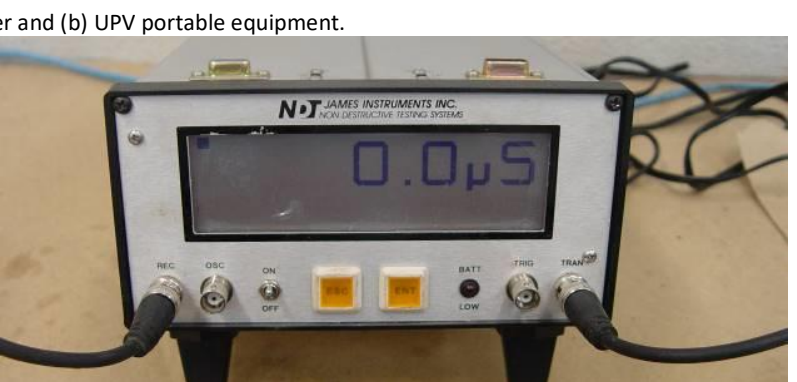

(b)

\section{A Short Review of the Principles of Ultrasonic Tests}

Among the NDT methods available, the ultrasonic tests allow the examination of homogeneity of the material. The use of these methods facilitates the defects diagnosis and concrete structures control during its lifetime. NDT can be essential to proceed with a technological control of concrete in the laboratory and situ. The applications of the tests are relatively easy to be conducted. The most important is to interpret the test results. The test measures the time that an ultrasonic pulse takes to cross a concrete section.

An impulse applied to a solid mass generates three types of waves. One of them, the surface waves, which has an elliptical particle displacement, is the slowest. On the other hand, the shear or transverse waves, which have particle displacement at right angles to the direction of travel, are faster. For last, the longitudinal waves with particle displacement in the direction of travel are the most important, since these are the fastest, and usually provide more useful information. This type of wave is primarily produced by the electro-acoustical transducers; other types generally cause little interference because of their lower speed (Bungey \& Millard, 1996).

Civil engineers have a considerable interest in the developments of ultrasonic methods for testing concrete because they offer a potentially powerful method of testing the concrete without damaging the structure. The original experiments took place at the same time and independently in Canada and Great Britain from 1946 to 1950, and formed the basis for subsequent developments in the subject. The difficulties in obtaining reproducible contact between transducers and concrete make it very difficult to obtain accurate measurements of pulse attenuation (Jones, 1963).

Ultrasonic Pulse Velocity: UPV is one of the most popular NDT used to assess the concrete properties (Lawson, Danso, Odoi, Adjei \& Quasie, 2011). The method is based on the propagation of a high-frequency sound wave through the material. The velocity of the ultrasonic pulse varies in response to the material density changes, allowing the estimation of the porosity and the detection of discontinuities.

The test improves the quality control, detects defects, measures the thickness of constituent layers of different materials, or characterizes the type of the concrete (Ercolani, Ortega \& Señas, 2007). For concrete tests, the method is generally based on the use of portable equipment, composed by the source/detector unit and handheld surface transducers, which works in the frequency range of 25 to $60 \mathrm{kHz}$ (ASTM, 1995). The determination of the longitudinal propagation characteristics of an ultrasonic pulse through a material is the basis of the UPV method. The method is widely used for the evaluation of concrete structures due to its effectiveness, simplicity, and low cost of application.

One of the most promising methods for the evaluation of concrete structures is the UPV method. This method examines the homogeneity of the material and uses the variations of some properties along time to provide better information about the actual conservation state of the structure.

These tests can also be the basis to explore the relation between concrete quality and compressive strength. The main idea is to explore the fact that ultrasonic velocity waves are a function of the density of the material and its correlation with the compressive strength. This relation is not always trustworthy and depends on several variables that can affect the concrete strength, including water-cement relation, size and type of aggregate, molding procedure, sample size, and cement type. 
In the case of concrete, the standards establish procedures for carrying out the tests, which are performed in order to determine concrete uniformity, to control its quality, to follow up the deterioration, to detect internal flaws and voids, to estimate the modulus of elasticity, and to monitor the variations at concrete characteristics (Taffe \& Mayerhofer, 2003). The same principle is the basis for the determination of the pulse velocity specified in basically all standards. Pulses of longitudinal elastic stress waves are generated by an electro-acoustical transducer directly in contact with the surface of the concrete sample. After traversing through the concrete, the pulses are received and converted into electrical energy by a second transducer (Komlos, Popovics, Nürnbergerová, Babál \& Popovics, 1996).

NBR 8802 (ABNT, 2016) indicates the use of UPV tests to check concrete uniformity, to detect internal concrete faults, to monitor the concrete characteristics, to evaluate the crack depth or other imperfections, to evaluate the modulus of elasticity and to estimate the concrete strength.

Measurement of the velocity of ultrasonic pulses of longitudinal vibrations passing through concrete may be used for the following applications (BSI, 1986):

a) Determination of concrete uniformity, which is most reliably achieved by taking measurements on a regular grid on the same member, or at comparable locations on similar members;

b) Detection of cracking and concrete voids, which will increase the effective path length resulting in a higher measured transit time;

c) In situ strength estimations, which are unlikely to have $95 \%$ confidence limits for concretes with compression strength superior to $\pm 7 \mathrm{MPa}$;

d) Strength development monitoring, which is possible after obtaining appropriate calibration charts;

e) Assessment of concrete deterioration, using a general comparative survey to locate suspect areas;

f) Estimation of layer thickness, in cases that the concrete may be suspected of having a sparse quality layer due to its manufacturing or any damage (fire, frost, or sulfate attack).

It is possible to use the UPV for specific purposes, such as evaluate the presence of concrete voids or detecting damages caused by fire (Lorenzi, 2009). An essential factor is that UPV allows proceeding with multiple tests in the same place in order to monitor concrete changes during the time. Through constant structure monitoring, it is possible to increase maintenance requirements.

Ultrasonic Tomography: Ultrasonic Tomography (UT) is an emerging method of NDT that assays concrete diagnostics and improves the quality assurance control during concrete structures construction and assist in rehabilitation decision. Detection of flaws using UT requires significant effort and user expertise (Hoegh \& Khazanovich, 2012). The objective of tomography is to provide visualization, either by cross-section or three-dimensional structure of the structure's interior, providing better identification of the anomalous regions (Bond, Kepler and Frangopol, 2000).

UT is assigned to control concrete structures, reinforced concrete, and stone with one side access in order to determine the integrity of the material in the structure. The presence of strange insertions, voids, not grouted areas, exfoliations, and cracks can also be detected. It also measures the thickness of the controlled object and provides information about the quality of the layer. It is applicable for concrete inspection, allowing imaging of the internal structure of objects from concrete, reinforced concrete, and different kinds of stones.

UT uses shear waves and a system capable of generating 3D tomography images of concrete elements, which enables the detection of flaws in concrete structures. The UT device contains forty transmitting and receiving DPC transducers with a default operation ultrasonic frequency of $55 \mathrm{kHz}$. The application of Dry Point Contact transducers has brought some new features to the methodology of materials evaluation as they allowed to increase the accuracy of ultrasonic data measurements (Nesvijsky, 1997).

This type of tomography also allows quick on-site assessment of material integrity. 3D image technique makes the results out most convenient to analyze. The experiences demonstrate that this user-friendly technology could be used to analyze deeper depths (Michaux \& Grill, 2009). This tool is an efficient way to create a three-dimensional representation of internal defects that may be present in a particular element and provides a comprehensive analysis of the generated images, being a quite useful tool in the evaluation of concrete elements (Schabowicz, 2014).

The UT used in this study utilizes 45 transmitting and receiving transducer pair measurements in a less than 3-second scanning, resulting in a 3D depth profile. The DPC transducers provide the necessary consistency of impact and wavefront penetration for a correct diagnostics. These transducers are retractable to adapt to the surface analyzed. The UT device has been specially designed to test concrete members in order to determine the size and location of defects 
in samples with unilateral access. The detection of cracks, air voids, and other failures, which may be empty or filled with a different material density or other physicomechanical properties from the surrounding concrete, besides the thickness of the specimen.

\section{The use of Ultrasonic Tests and Image Analysis for Concrete Monitoring}

The evaluation of ultrasonic test results is a highly specialized and complex activity, which requires careful data collection, expert knowledge, and sensitivity to obtain a reliable diagnosis. The applications of ultrasonic tests are an exciting strategy to monitor the state of concrete structures constantly. These techniques are seen as a viable and adequate strategy to develop such tools.

The significant challenge for monitoring concrete structures through ultrasonic tests and image analysis consists of collecting, organizing, and extracting data from the tests to support a correct perception of this type of structure. The methods can be considered as one of the most promising approaches for evaluation of the concrete structures once it makes possible an examination of material homogeneity. The main test objective was to collect data and verify if the analysis of the results could allow the detection of the objects inside the beam. The interpretation of results occurred through the surface mapping technique.

In this direction, the Research Group of LEME-UFRGS developed a technical image analysis based on rosette patterns using topographic software. The study of the surface contour maps created using the UPV data indicated that the use of the values obtained from indirect measurements seemed to create images that were better fitted to the known position of the defects. UPV propagation at concrete is very sensitive to the presence of flaws, cracks, or other discontinuities. The mapping was performed by indirect measurement technique which has proved appropriate to map the surfaces, allowing to detect voids and defects (Lorenzi, Reginato, Favero \& Silva Filho, 2013), (Lorenzi, Caetano, Drunn \& Silva Filho, 2003), (Lorenzi, Silva Filho, Caetano, Campagnolo \& Strieder, 2004), (Lorenzi, Caetano \& Silva Filho, 2005), (Lorenzi, Silva Filho, Campagnolo, Caetano \& Fischer, 2006), (Lorenzi, Caetano, Campagnolo \& Silva Filho, 2009), (Lorenzi, Lorenzi, Caetano \& Silva Filho, 2010), (Lorenzi, Silva Filho, Campagnolo \& Caetano, 2012), (Lorenzi, Silva Filho, Caetano \& Chies, 2014), (Lorenzi, Caetano, Campagnolo, Lorenzi \& Silva Filho, 2015).

The use of this methodology brought promising results with significant technical and financial impact in the evaluation of concrete structures. The mapping of concrete structures using UT seems like a new trend in the concrete structure evaluation. The practical applications of UPV and UT mapping served as the basis for this study.

Results and Discussion

\section{Report of Practical Case Studies Applications}

The LEME/UFRGS group performed practical applications of UPV and UT at four case studies. The first and second cases involved the use of UT on a bridge deck and a slab composed of precast hollow-core elements, respectively. The third and fourth cases illustrate the UPV application in reinforced concrete structures to detect differences in concrete homogeneity.

Case Study 1: This study involved the use of UT to evaluate one bridge deck located at the university campus, which had a history of poor structural performance and deterioration. The data collection occurred with the use of a UT scanner regarding the concrete deck condition. A $10 \times 25 \mathrm{~cm}$ grid applied to two regions of the top surface of the bridge deck served as a basis to take measurements, as shown in Figures 2 and Figure 3. The visual inspection of the bridge determined the areas of interest of this research.

The research group was looking to find if there were internal defects or flaws in the bridge deck. The scan was performed using a frequency of $50 \mathrm{kHz}$ and a pulse ratio of $3050 \mathrm{~m} / \mathrm{s}$. After acquiring the data from each rosette patterned grid, the results interpreted with software that generates a 3D image of the reflected element interfaces. The image generation made it possible to identify different interfaces presented at the bridge deck.

Figure 3 shows some of the test results, where it is possible to see differences in concrete homogeneity. All images generated similar patterns. The deep blue color represents points where the homogeneity of the concrete is higher, while the reddish regions show potential flaws or defects. The general condition, as indicated by these results, was good, but small faults and errors could be detected near the surface, especially at casting interfaces, as seen in the images. 
Figure 2. (a) and (b) 3D Tomography to evaluate a bridge deck.

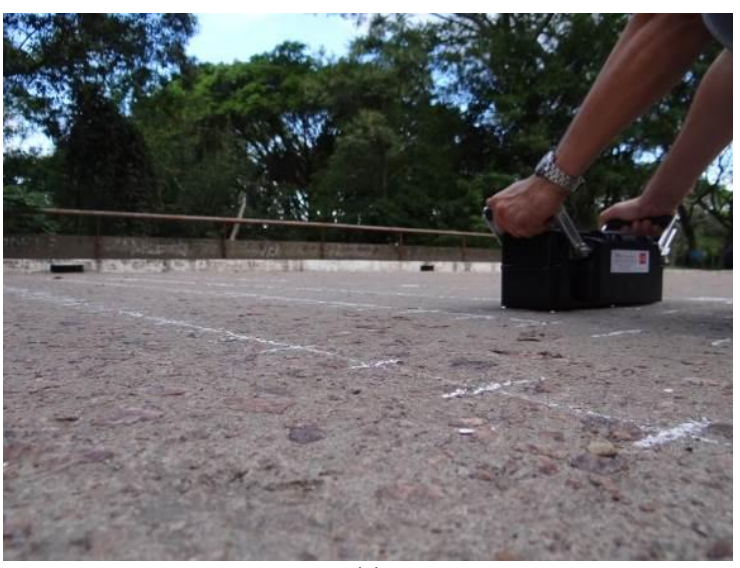

(a)

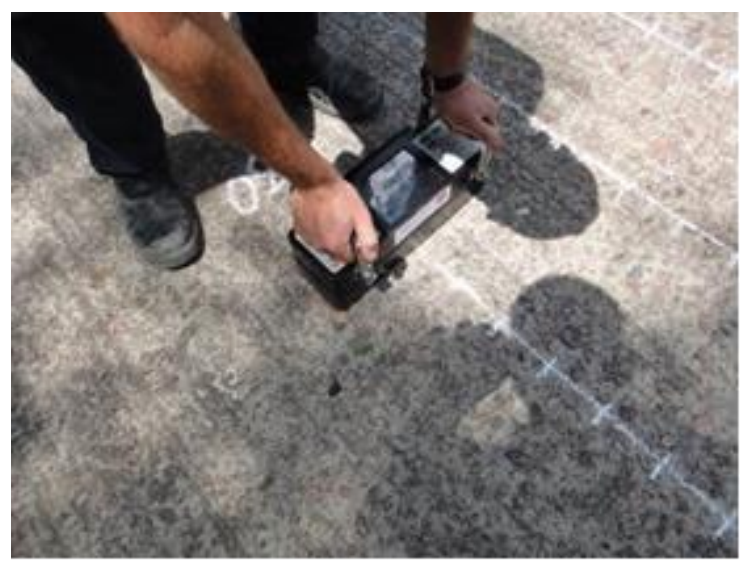

(b)

Figure 3. (a) and (b) Bridge deck evaluation through UT.

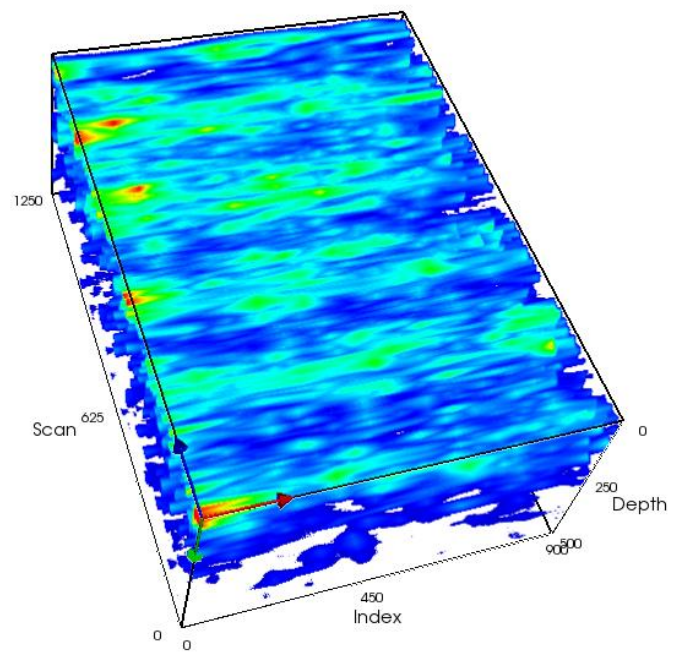

(a)

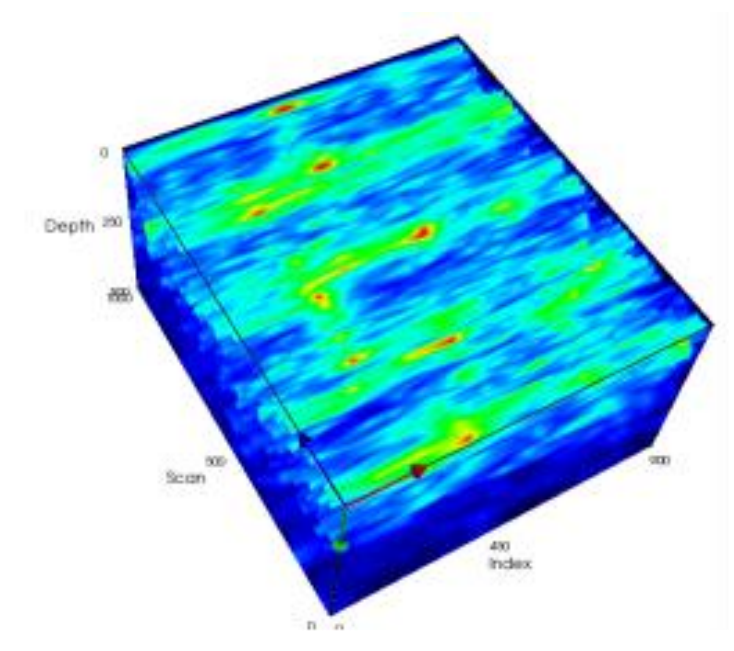

(b)

Visual indications of small defects and flaws could be seen in most areas near the surface. The UT represents these areas through lower readings. Figure 4 shows one of these surface defects and its location at the ultrasonic tomography image.

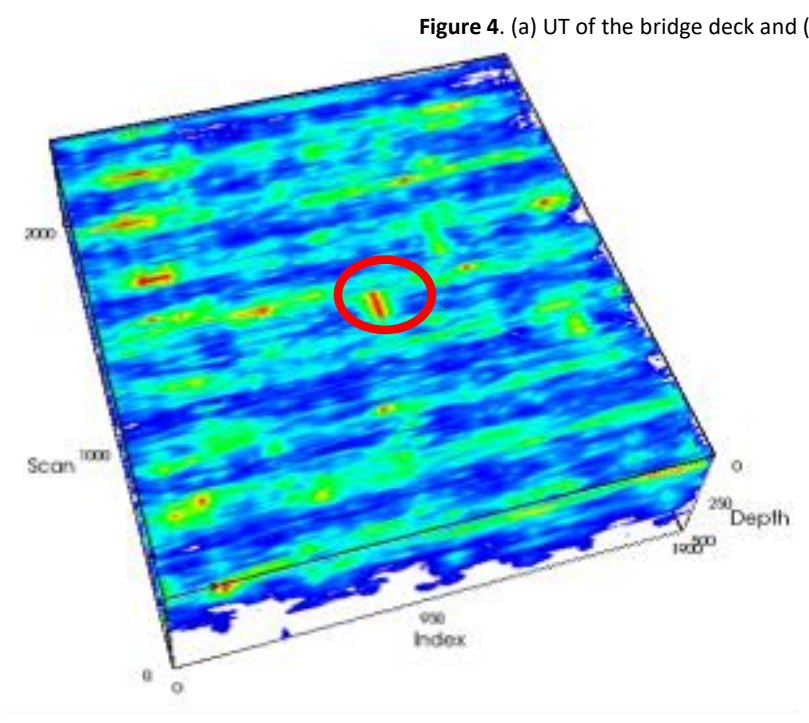

(a)

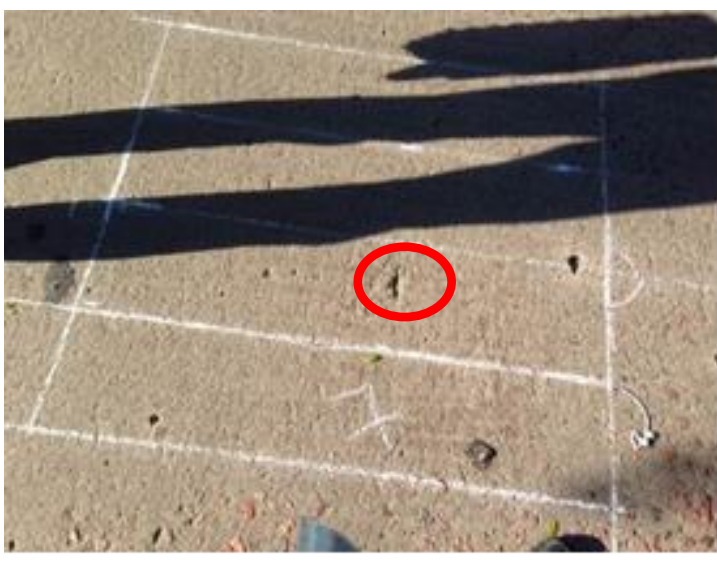

(b) 
Case Study 2: the second case study involved the application of the same UT device to detect the location of precast hollow-core slabs used in a building structure. Figure 5 (a) shows a schematic cross-section of the slabs analyzed, and Figure 5 (b) indicates the location and position of the grid that served as the basis for the data acquisition. In this case, the UT device used a frequency of $70 \mathrm{kHz}$ and a pulse velocity of $3040 \mathrm{~m} / \mathrm{s}$.

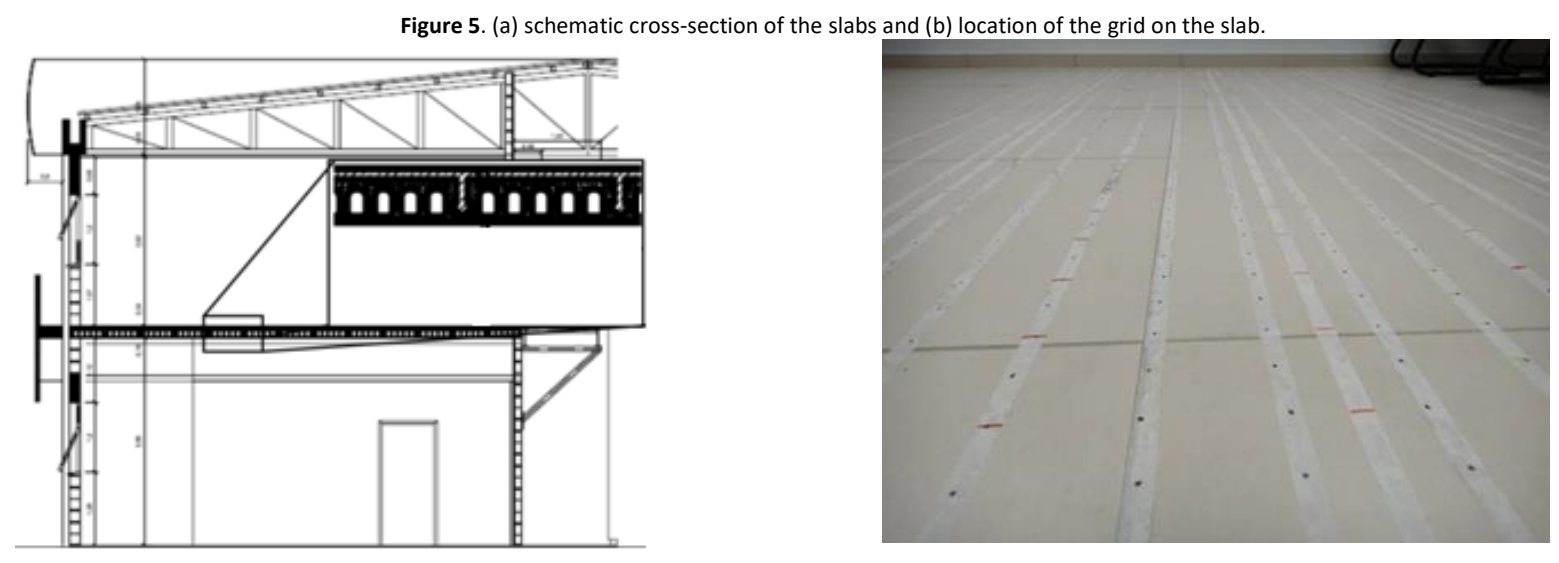

(a)

(b)

The main research objective was to analyze the level of detail that can be captured by 3D tomography, varying the size of the grid. The test configuration was based on the maximum grid recommended by the manufacturer $(10 \times 25 \mathrm{~cm})$, and also on a smaller grid of $5 \times 10 \mathrm{~cm}$, created by the research group. The second grid allowed the overlapping of the data readings. Figure 6 shows the top view of the 3D tomography from the slab obtained with the $5 \times 10 \mathrm{~cm}$ grid. The location of the hollow cores is quite precise. Figure 7 presents a cross-section of the analyzed slab. The image received digital treatment to show just the readings for the hollow cores, allowing an estimation of their dimension, spacing, shape, and distance to the surface of the slab.
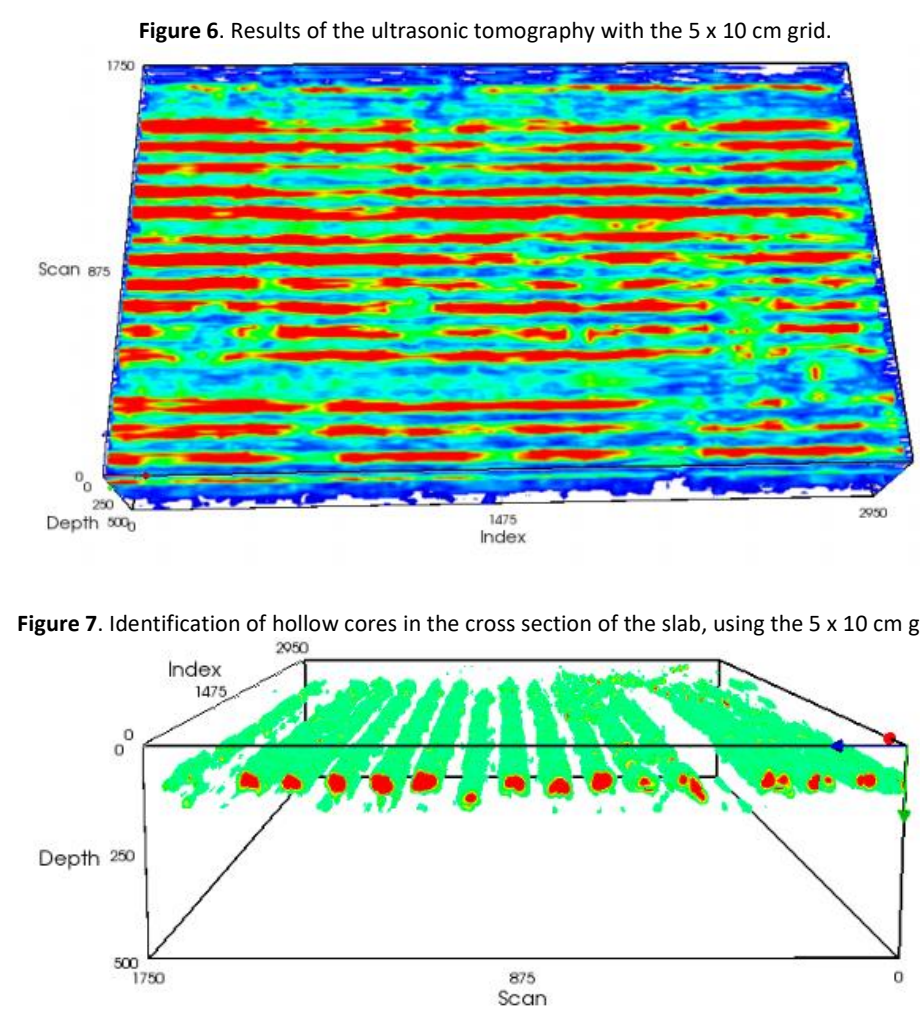

The measurements obtained from the $10 \times 25 \mathrm{~cm}$ grid had a reduction on the level of detail represented in the 3D scan, as shown in Figure 8. Although the hollow cores are still perceptible in the image, a general loss of quality happened, compromising a more refined and precise analysis. This indicates that both grids can provide good quality data, although 
the smaller the grid, the better the quality of the images, which makes it costly and increases the time consumption. So, it is necessary to decide the level of detail the procedure needs to have and if it is worth doing in each particular case.

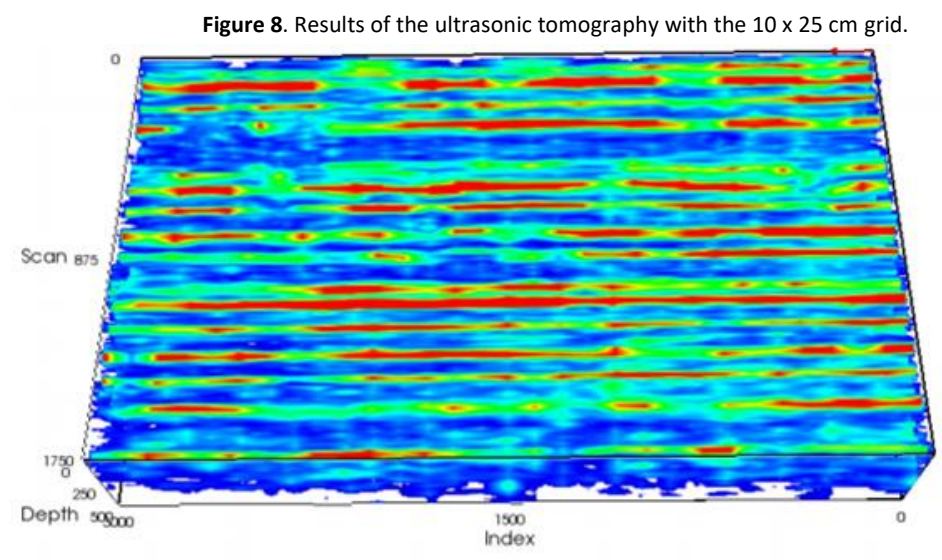

Case Study 3: this case study presents the test results of a UPV performed in mass concrete elements. The examined structures are part of some structural elements in which the technological control indicated potential problems regarding compressive strength. The main objective was to map the concrete homogeneity of these elements of interest through a UPV analysis and compare these results with the ones obtained from a concrete element in which the control specimens presented satisfactory results. After the comparison, the compressive strength was acceptable with a high confidence level.

The UPV variations were graphically mapped through specific software, facilitating the visualization of the changes in the concrete uniformity, its compactness, and the integrity of each element. For guiding the measurements, reference grids were traced on the lateral surfaces of these elements. This grid was slightly adjusted to make it compatible with the dimensions of the examined elements.

The mapping of the element, shown in Figure 9, had a $25 \times 25 \mathrm{~cm}$ grid to facilitate the location of the reading points. The concrete surface received treatment to reduce the roughness and allow better contact between the transducer and the element. The strategy was positioning the transmitting transducer at the midpoint of a quadrant, and the receiving transducer at eight standard positions around the first sensor, resulting in eight UPV readings for the same quadrant. A color scale illustrates the UPV changes, with a range between $1600 \mathrm{~m} / \mathrm{s}$ (deep red) and $5400 \mathrm{~m} / \mathrm{s}$ (deep blue).

Figures 9 and 10 show the images generated from a mass concrete foundation block. The UPV results involve velocities between 2400 to $2800 \mathrm{~m} / \mathrm{s}$. In general, this range of speed would indicate regular quality concrete, characterized to have more compact areas at its bottom and less compact areas on the top.

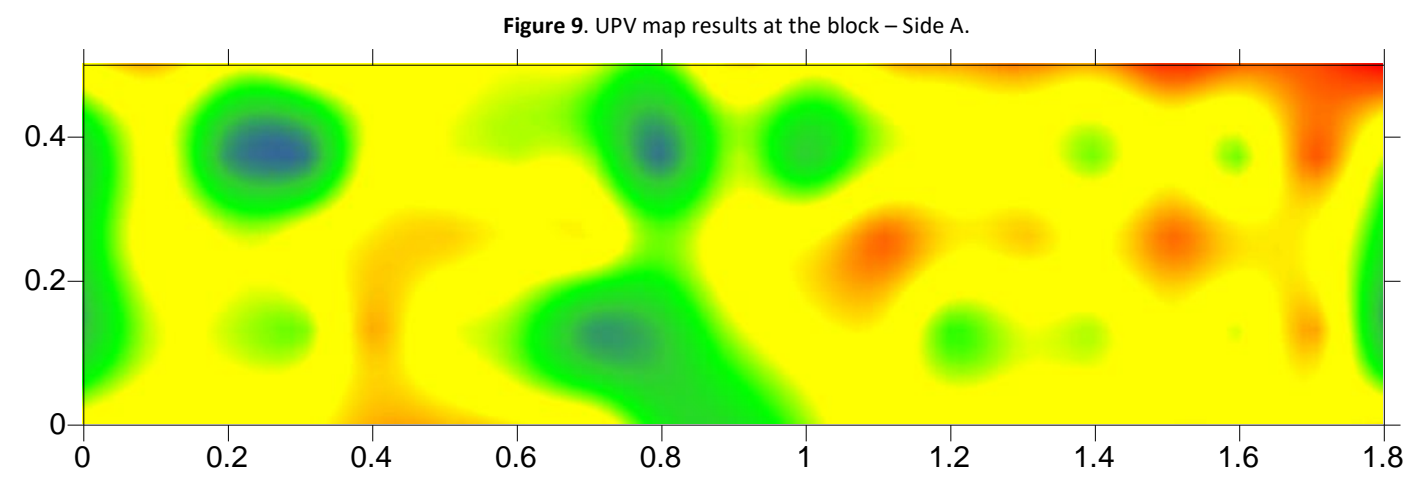




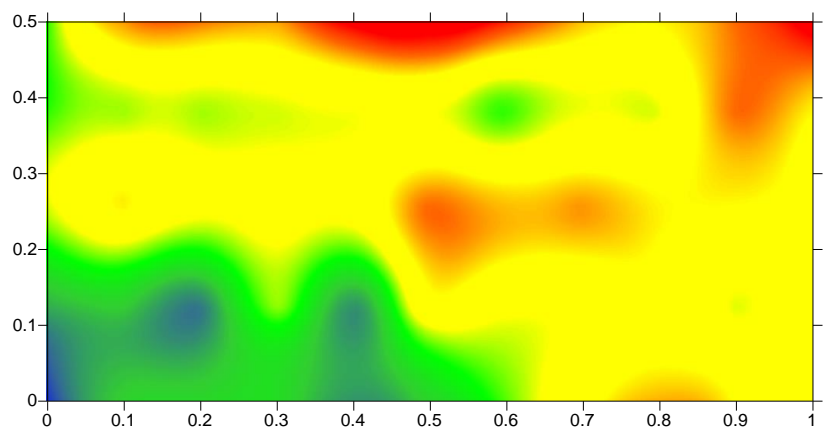

Case Study 4: the study objective was to verify the concrete homogeneity of a section of a barrage by using UPV mapping. There were problems during the molding of the columns. When the sliding forms were raised, they dragged some concrete with them, which contributed to the formation of concrete voids and flaws, just below the surface.

Given the lack of visual indications on the surface, percussion, and UPV mapping were used to find regions where repairs were necessary. The mapping was done using indirect measurements and a surface grid, a technique that demands sensitivity and experience, but has been useful to map surfaces and detect subsurface voids and defects in laboratory and field applications.

The variations in UPV readings were graphically mapped using software that generates contour lines to show the concrete homogeneity of each element. The analysis of the surface contour maps created from the UPV data indicated the location of potentially problematic areas. As shown in Figure 11, the images present local variations of concrete homogeneity. These variations can be associated with the presence of voids.

The readings obtained using $20 \times 20 \mathrm{~cm}$ to $100 \times 100 \mathrm{~cm}$ grids served as the basis for the confection of the UPV maps. The suspicious regions were located with the use of the more extensive range grids; the subdivision of these grids was done later to improve the diagnosis.

Figure 11 shows the images generated in two piers. It is possible to identify regions where the surface concrete had poor adhesion to the underlying material. The graphic and statistic analysis of the results combined with the visual inspection and percussion evidence determined the regions that need repair reliably. The results indicate that the general condition of the remaining concrete at this element was quite good.

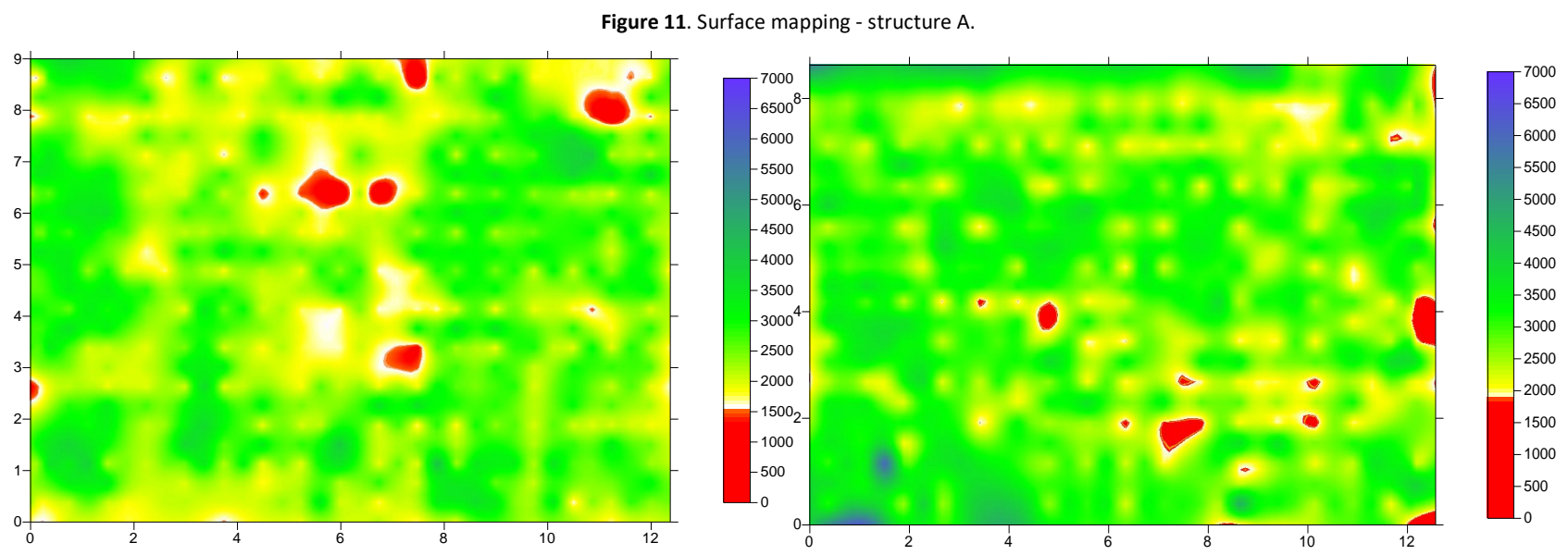

Figure 12 shows the UPV map of another part of the structure. The results indicate that large portions of the surface needed intervention. A detailed analysis with a smaller grid was performed to map these regions and indicated the presence of a large number of voids, as shown in Figure 13. Besides this, core extractions to ensure the diagnosis were also made. The analysis of cores was useful because it permits an improved diagnosis by allowing the establishment of the range of UPV results that corresponded to unacceptable voids in the structure. 


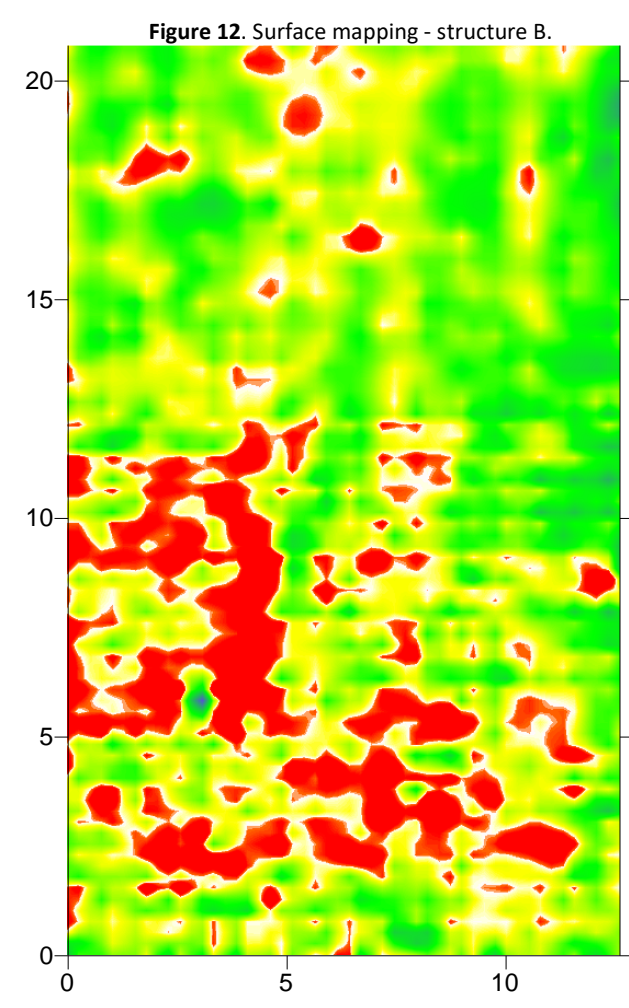

Figure 13. Visual examination of extracted cores in the structure B.
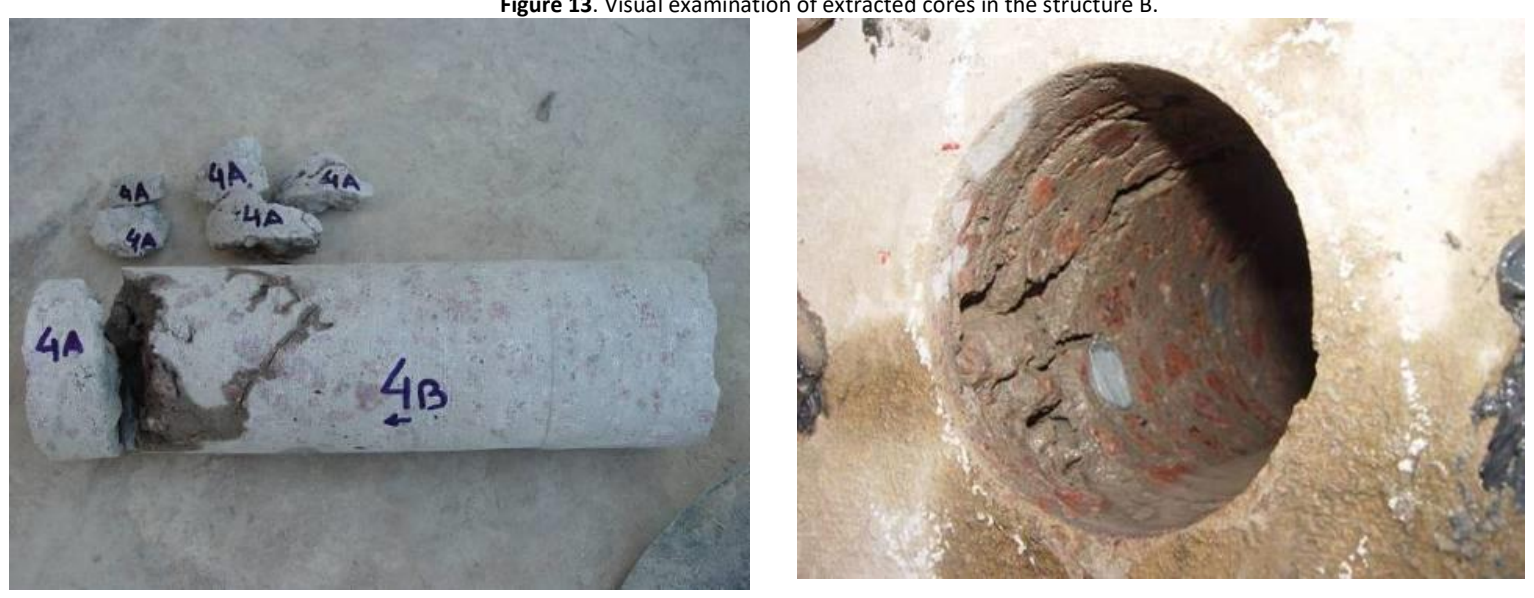

Conclusions

Many efforts have been made in NDT research to control concrete structures with high quality and durability. Researchers have sought to understand the capabilities and limitations of NDT tests. The use of NDT can assist in decision making and the establishment of maintenance or intervention strategies in concrete structures.

Ultrasonic NDT tests can be very used in such cases, as demonstrated in the case studies analyzed. The key factor is to decide which technique is more suitable for each case, considering the level of detail, cost, and complexity. Both UPV and UT are useful to evaluate the condition of concrete structures. However, they require time, access, knowledge, and high sensibility to analyze patterns and correlate them to the specific situation.

This research provides clear evidence of the potentialities of using UPV and UT to evaluate the condition of concrete structures. These techniques can locate relatively small defects in concrete structures, which could represent problems in terms of structural performance. Both tests are susceptible to homogeneity and density variations and can provide essential data for decision making about the conditions of concrete structures. The use of a contour mapping technique was demonstrated to be an adequate way to organize and interpret the results of UPV tests in order to detect suspicious zones. The use of grids to collect data is an excellent way to structure the test and make sure that no region is overseen. 
The UT test is an efficient way to create a three-dimensional representation of internal defects that may be present in a particular element and provides a comprehensive analysis of images generated that can be quite useful in the evaluation of concrete elements.

In some of the case studies presented in this paper, NDT data was used for critical decision making, enabling the choice of the best action based on technical data that was adequately reliable, in-depth, and covered the whole of the structures.

In general, NDT tests can play an essential role in determining the existence of defects in concrete structures. However, more work must be done to establish the reliability and detection threshold of each technique.

Acknowledgement

\section{The authors are grateful for the support of the Laboratório de Ensaios e Modelos Estruturais da Universidade Federal do Rio Grande do Sul.}

ABNT (Associação Brasileira de Normas Técnicas). (2016). NBR 8802: Concreto Endurecido - Determinação da Velocidade de Propagação da Onda Ultrassônica: Método de Ensaio. Rio de Janeiro.

ASTM (American Society for Testing and Materials). (1995). Standard Practice for Ultrasonic Pulse-Echo Straight-Beam Examination by the Contact Method. Annual Book of ASTM Standards, Vol. 03.03., Philadelphia. USA.

Bond, L. J.; Kepler, W. F.; \& Frangopol, D. M. (2000). Improve Assessment of Mass Concrete Dams using Acoustic Travel Time Tomography, Construction Building Materials, 14, 133-146.

Breysse, D., (2009-june). How to improve the quality of concrete assessment by combining several NDT measurements. Proceedings of International Symposium on Non-Destructive Testing in Civil Engineering, Nantes, France, 7.

BSI (British Standards Institution). (1986). BSI 1881 - Part 203: Recommendations for measurement of velocity of ultrasonic pulses in concrete. London, $20 \mathrm{p}$.

Bungey, J. H., Millard, S. G. (1996). Testing of Concrete in Structures, Glasgow: Chapman \& Hall.

Chekround, M., Le Marrec, L., Abraham, O., Villain, G., \& Durand, O. (2009, junho). Analysis of coherent surface wave dispersion and damping for non destructive testing of concrete. Proceedings of International Symposium on Non-Destructive Testing in Civil Engineering, Nantes, France, 7.

Ercolani, G. D., Ortega, N. F., \& Señas, L. (2007-october). Empleo de Ultrasonidos y Esclerometría em el diagnóstico de Estructuras de Hormigón Afectadas por Elevadas Temperaturas. Proceedings of Conferencia Panamericana de END, Buenos Aires, Argentina, 4.

Grabowski, S. L., Padaratz, I. J., \& Pinto, R. C. A. (2008, october). Avaliação de Placas de Concreto com o Método Não Destrutivo do Eco-impacto. Anais do Congressso Brasileiro do Concreto, Salvador, BA, Brasil, 50.

Hoegh, K.; \& Khazanovich, L. (2012). Correlation Analysis of 2D Tomographic Images for Flaw Detection in Pavements, ASTM Journal of Testing and Evaluation, 40, 247-255.

Jones, R. (1963). The Ultrasonic Testing of Concrete. Ultrasonics, 1(2).

Komlos, K., Popovics, S., Nürnbergerová, T., Babál, B., \& Popovics, J. S. (1996). Ultrasonic Pulse Velocity Test of Concrete Properties as Specified in Various Standards, Cement and Concrete Composites, 18, 357-364.

Lawson, I., Danso, K. A., Odoi, H. C., Adjei, C. A., \& Quasie, F. K. (2011). Non-Destructive Evaluation of Concrete using Ultrasonic Pulse Velocity. Research Journal of Applied Sciences, Engineering and Technology, 6(3).

Lorenzi, A. (2009). Aplicação de redes neurais artificiais para estimativa da resistência à compressão do concreto a partir da velocidade de propagação do pulso ultra-sônico. Tese de doutorado, Universidade Federal do Rio Grande do Sul, Porto Alegre, RS, Brasil. 2009. Access: https://lume.ufrgs.br/handle/10183/25985.

Lorenzi, A., Caetano, L. F., Campagnolo, J. L., \& Silva Filho, L. C. P. (2009-junho). An investigation of the suitability of different NDT test methods to detected voids of concrete elements. Proceedings of International Symposium on Non-Destructive Testing in Civil Engineering, Nantes, France, 7 .

Lorenzi, A., Caetano, L. F., Drunn, M. T., Silva Filho, \& L. C. P. (2003-june). Utilização de Ultra-som para o Monitoramento de Estruturas de Concreto. Proceedings of Conferencia Panamericana de END, Rio de Janeiro, Brasil, 3.

Lorenzi, A., Caetano, L. F., Silva Filho, \& L. C. P. (2005-june). Using Ultrasonic Pulse Velocity for Monitoring Concrete Structures. Proceedings of the U.S.-Japan Symposium on Advancing Applications and Capabilities in NDE, Maui, United States, 3.

Lorenzi, A., Campagnolo, J. L., Silva Filho, \& L. C. P. (2006). Application of artificial neural network for interpreting ultrasonic readings of concrete. Int. J. Materials and Product Technology, 26(1-2), 57-70. 
Lorenzi, A., Lorenzi, L. S., Caetano, L. F., \& Silva Filho, L. C. P. (2010-june). Strategies for Monitoring Concrete Structures by Means of Ultrasonic Pulse Velocity. Proceedings of Structural Faults \& Repair, Edinburgh, Scotland, 13.

Lorenzi, A., Reginato, L. A., Favero, R. B., Chies, J. A., Caetano, L. F., \& Silva Filho, L. C. P. (2013). Tomografia Ultrassônica 3D para Avaliação de Estruturas de Concreto, Téchne: Revista de Tecnologia da Construção, 198, 36-44.

Lorenzi, A., Silva Filho, L. C. P., Caetano, L. F., \& Chies, J. A. (2014). Investigation of the Potential for Evaluation of Concrete Flaws Using Nondestructive Testing Methods. ISRN Civil Engineering, v.2014, 1-8.

Lorenzi, A., Silva Filho, L. C. P., Caetano, L. F., Campagnolo, J. L., \& Strieder, A. J. (2004-october). Using Non-Destructive Testing for Monitoring Concrete elements of Sizable Structural Members. Proceedings of the Structural Materials Technology, Buffalo, United States, 6.

Lorenzi, A., Silva Filho, L. C. P., Campagnolo, J. L., \& Caetano, L.F. (2012). Analyzing two different data processing strategies for monitoring concrete structures using ultrasonic pulse velocity. Revista ALCONPAT, 2(1), 192-204.

Lorenzi, A., Silva Filho, L. C. P., Campagnolo, J. L., Caetano, L. F., \& Fischer, S. A. (2006). Análise de Estruturas de Concreto através de Ensaios de Velocidade de Propagação do Pulso Ultra-sônico. Proceedings of Jornadas Sulamericanas de Engenharia Estrutural, Campinas, Brasil, 32.

Lorenzi, A., Caetano, L. F., Campagnolo, J. L., Lorenzi, L. S., \& Silva Filho, L. C. P. (2015). Application of Ultrasonic Pulse Velocity to Detect Concrete Flaws, E-Journal of Nondestructive Testing and Ultrasonics, v. 11. Access: http://www.ndt.net.

Michaux, C.; \& Grill, M. (2009). NDT 3D Tomographic Testing Cases on Concrete and National Heritage Buildings, ACl Chapter - Sevilha. Access: http://www.germann.org/.

Molero Armenta, M. A., Segura, I., Hernández, M., Garcia Izquierdo, M. A., \& Anaya, J. (2009-june). Ultrasonic characterization of cementitious materials using frequency-dependent velocity and attenuation. Proceedings of International Symposium on Non-Destructive Testing in Civil Engineering, Nantes, France, 7.

Nesvijsky, E. G. (1997). On the Problem of Application of the Conic and Exponential Wave Guiding Extensions for Ultrasonic Transducers for Materials Testing, NASTA Technical Bulletin, 3, 49-56.

Ploix, M. A., Garnier, V., Breysse, D., \& Moysan, J. (2011). NDT Data Fusion for Evaluating Concrete Structures. Review of Progress in Quantitative Nondestructive Evaluation, Burlington, USA, 30.

Schabowicz, K. (2014). Ultrasonic tomography - The latest nondestructive technique for testing concrete members - Description, test methodology, application example, Archives of Civil and Mechanical Engineering, 14, 295-303.

Shah, S., Popovics, J. S., Subramaniam, K. V., \& Aldea, C., (2000). New Directions in Concrete Health Monitoring Technology. Journal of Engineering Mechanics, 126(7), 754-760.

Taffe, A., \& Mayerhofer, C. (2003-september). Guidelines for NDT methods in civil engineering. Proceedings of International Symposium on NonDestructive Testing in Civil Engineering, Berlin, Germany, 6.

Wiggenhauser, H. (2009-june). Advanced NDT Methods for Quality Assurance of Concrete Structures. Proceedings of International Symposium on Non-Destructive Testing in Civil Engineering, Nantes, France, 7. 